\title{
A Cross Sectional Analysis Of Dietary Practices And Nutrition Status Of Female Undergratuate Students At Kenyatta University, Kenya
}

Grace Waweru ( $\nabla$ gray.waweru@gmail.com )

Kenyatta University School of Applied Human Sciences https://orcid.org/0000-0001-8348-5346

Peter Chege

Kenyatta University

Eunice Njogu

Kenyatta University

Research article

Keywords: Dietary practices, female students, nutrition status, body mass index

Posted Date: October 11th, 2019

DOI: https://doi.org/10.21203/rs.2.12334/v2

License: (1) This work is licensed under a Creative Commons Attribution 4.0 International License.

Read Full License

Version of Record: A version of this preprint was published at American Journal of Food Sciences and Nutrition on October 25th, 2021. See the published version at https://doi.org/10.47672/ajfsn.528. 


\section{Abstract}

Background The rapid changes in eating habits and lifestyles in Kenya have resulted to the overweight/obesity transition. Students are likely to make poor food choices which may affect their nutrition status during the beginning of college and this may continue throughout their life. This study aimed to establish the dietary practices, assess nutrition status based on body mass index and the relationship between selected dietary practices and nutrition status of female undergraduate students at Kenyatta University, Kenya.Method s: The study adopted a cross-sectional analytical design involving sample of 422 female undergraduate students randomly selected from Kenyatta University. Food Frequency Questionnaire and the Minimum Dietary Diversity - Women were used to assess dietary practices. Weight and height were measured to assess the nutrition status of the female students. Results The results showed that $64.0 \%$ of the participants had consumed $\geq 5$ food groups while $36 \%$ had consumed $<5$ food groups over a period of 24 hours. In terms of nutrition status, $68.4 \%$ of the participants had normal BMI while $23.9 \%$ were overweight, $5.55 \%$ were underweight and $2.3 \%$ were obese MDDS-W was significantly associated with nutrition status $(p=0.044)$.Conclusion The results illustrated unhealthy eating habits and sub-optimal nutrition status among a significant number of the female students. Policy makers should scale up interventions that would help improve dietary practices of women of reproductive age particularly university students.

\section{Background}

Kenya, like many developing countries has been experiencing rapid changes in dietary habits and lifestyles resulting to the overweight/obesity transition. Students are likely to make poor food choices which may affect their nutrition status during the beginning of college and this may continue throughout their life. ${ }^{[1-2]}$ Young adults' feeding practices have been characterized with frequent snacking, overweight/obesity and skipping of meals particularly breakfast. ${ }^{[1]} \mathrm{A}$ study conducted in a Zimbabwe University associated students' poor choices in food with inadequate nutrition knowledge and their failure to understand their nutrition requirements. ${ }^{[3]}$ Another study among female undergraduate students attending various universities in Nairobi revealed that most of the students did not get the recommended daily meals. ${ }^{[4]}$

An individual's nutrition status results from interrelated factors that are influenced by the quantity and quality of food consumed and physical health. Three hundred million women in the world are estimated to be obese making obesity a global health problem. The prevalence is even higher in urban areas where the level of obesity in Kenya is now approaching 50\% among women in urban areas, aged between 19 and 49 years. ${ }^{[5]}$ A study among undergraduate students in Nairobi showed that $22.9 \%$ of the students were overweight and obese while $5.5 \%$ were underweight. ${ }^{[4]}$ Evidence suggests that a young female adult's nutrition status has important effects for her health and the health of her children and is an important factor in breaking the malnutrition cycle. ${ }^{[6]}$ 
Various studies have demonstrated a positive correlation between good dietary practices and a woman's nutrition status, menstruation, ovulation, the likelihood of conception and pregnancy outcomes. [7-9]

The purpose of this study was to determine the dietary practices, assess the nutrition status and establish the relationship between dietary practices and nutrition status among female students at Kenyatta University.

\section{Methods}

A cross-sectional analytical study design was adopted in the study. The study population included female undergraduate students at Kenyatta University, Kenya. Kenyatta University is a public university in Kenya located 16 kilometers from Nairobi city. The University was chosen purposively as it consist a high number of students with diverse social, economic and cultural backgrounds. A total of 422 students were selected to participate in the study but 32 had incomplete questionnaires hence the final analysis included 390 students.

\section{Data Collection and statistical analysis}

Data was collected using a researcher administered questionnaire. A Food Frequency Questionnaire (FFQ) and the Minimum Dietary Diversity - Women (MDD-W) was used to assess dietary practices. Weight was taken using a salter scale and height using a stadiometer.

Data obtained was analyzed using Statistical Package for Social Sciences (SPSS) version 22 for windows. Descriptive statistics like mean, standard deviations and percentages were used to describe the study population. To determine the MDDS of the students, a point was awarded to each food group consumed over the reference period and a sum computed for all points. ${ }^{[10]}$ Adequate consumption was based on consumption of five or more food groups. Food Frequency was determined based on how many times a food group was consumed over a one week period. BMI was used to assess nutrition status. The BMI was classified as either underweight $\left(<18.5 \mathrm{~kg} / \mathrm{M}^{2}\right)$, normal $\left(18.5-24.99 \mathrm{Kg} / \mathrm{M}^{2}\right)$, overweight $(25-$ $\left.29.99 \mathrm{Kg} / \mathrm{M}^{2}\right)$ and obese $\left(>30 \mathrm{Kg} / \mathrm{M}^{2}\right)$.

Chi-square test was used to establish relationship between dietary practices and nutrition status. In all the analyses, a $P$ value of $<0.05$ was considered significant.

\section{Results}

\section{Dietary practices among female students}

\section{Frequency of consumption of various foods among the respondents}

Table 1 below shows results from the 7 day food frequency questionnaire. The food group most frequently consumed was cereals and cereal products with $59.5 \%$ of the respondents consuming daily. 
Milk and milk products were consumed everyday by $24.7 \%$. Only $11.8 \%$ of the students consumed meat, poultry and their products every day and while $2.9 \%$ never consumed. Fruits and vegetables were consumed everyday by $38.5 \%$ and $47.1 \%$ of the students, respectively. Beverages were consumed by 45.4 $\%$ of the students every day.

\section{Table 1: Frequency of food consumption}

\begin{tabular}{|l|l|l|l|l|}
\hline Food type & \multicolumn{4}{|l|}{ Frequency per week } \\
\hline & Everyday & $\begin{array}{l}\mathbf{1 - 2} \text { times } \\
\text { a week } \\
(\%)\end{array}$ & $\begin{array}{l}\text { 3-6 times } \\
\text { a week } \\
(\%)\end{array}$ & $\begin{array}{l}\text { Never } \\
\text { consumed } \\
\text { (\%) }\end{array}$ \\
\hline Cereals and cereal products & 59.5 & 17.8 & 22.7 & - \\
\hline Roots and tubers & 4.9 & 62.4 & 16.4 & 16.4 \\
\hline Milk and milk products & 24.7 & 45.7 & 19.8 & 9.8 \\
\hline Meat, poultry \& products & 11.8 & 58.0 & 27.3 & 2.9 \\
\hline Legumes and nuts & 25.9 & 46.6 & 21.3 & 6.3 \\
\hline Fruits & 38.5 & 35.9 & 25.0 & 0.6 \\
\hline Vegetables & 47.1 & 29.9 & 19.8 & 3.2 \\
\hline Sweets & 34.5 & 34.2 & 19.5 & 11.8 \\
\hline $\begin{array}{l}\text { Beverage; soft drinks, fresh juice,Fresh } \\
\text { squash, tea, cocoa }\end{array}$ & 45.4 & 31.3 & 17.2 & 6.0 \\
\hline $\begin{array}{l}\text { Others; Sausages, Smokies, Hotdogs, } \\
\text { pizza }\end{array}$ & 9.5 & 50.9 & 19.8 & 19.8 \\
\hline
\end{tabular}

\section{Minimum dietary diversity score}

The mean MDDS was $5.11 \pm 1.66$ with a minimum score of 0 and a maximum score of 10 food groups. More than half of the respondents $(64 \%)$ had consumed $\geq 5$ food groups while $36 \%$ had consumed $<5$ food groups (Figure 1).

\section{Nutrition status of the respondents}

The mean height of the respondents was $160.3 \pm 6.5 \mathrm{SD} \mathrm{cm}$. The lowest height was $139 \mathrm{~cm}$ while the highest height was $179 \mathrm{~cm}$. The mean weight was $58.7 \pm 9.3$ SD kg with the lowest and highest weight being $36 \mathrm{~kg}$ and $88 \mathrm{~kg}$, respectively. The mean BMI was $23 \pm 3.1$ SD with a low of $15 \mathrm{~kg} / \mathrm{m}^{2}$ and a high of $34.9 \mathrm{~kg} / \mathrm{m}^{2}$. Generally, $68.4 \%$ of the respondents had normal BMI while $23.9 \%$ were overweight, $5.55 \%$ were underweight and $2.3 \%$ were obese (Figure 2). 
Table 2 shows results of chi-square test between MDDS-W and nutrition status. The test revealed a significant relationship between dietary diversity-women and nutrition status of the respondents $\left(\chi^{2}\right.$ $=7.214, \mathrm{df}=1, \mathrm{p}=0.044)$.

Table 2: Relationship between Knowledge, Attitudes on Pre-conception Dietary Practices and Dietary practices

\begin{tabular}{|l|l|l|}
\hline Variable & \multicolumn{2}{|l|}{$\mathrm{N}=390$} \\
\hline MDDS-W vs. & $\chi^{2}$ & P value \\
\hline Nutrition status & 7.214 & $0.044^{*}$ \\
\hline
\end{tabular}

* Significance at $\mathrm{p}<0.05$

\section{Discussion}

The young population in university contributes to the poor eating habits among university students. $[4,11-$ 12] Junk food makes up the main meals for most young people in urban and peri-urban centres.

The respondents of this study had an adequate MDDS with a mean of $5.11 \pm 1.66$. The results compare with previous studies. ${ }^{[13-14]}$ However, these previous studies considered a total of 13 and 8 food groups, respectively in contrast to this study which considered 10 food groups. The higher dietary diversity could be attributed to the affordability of meals in the University's cafeterias and the nearby market where most of the students get their meals from. The low consumption of nuts and seeds observed among the respondents could be as a result of financial constraints.

From the 7 day food frequency, several undesirable food habits were observed among the respondents in this study including consumption of sweets with about $88.8 \%$ of the students consuming at least once in a week, intake of beverages with $45.4 \%$ of the students consuming every day and foods like sausages, smokies and hotdogs being consumed by $50.9 \%$ of the respondents every day. Excess intake of these foods has been associated with diabetes, overweight, obesity and cardiovascular diseases. ${ }^{[15]}$ Similar results have been reported in previous studies. ${ }^{[1,3-4]}$ The frequent consumption of these unhealthy foods could be attributed to the ease in access of these foods in the university's cafeterias, tuck shops and a nearby local market. An additional contributing factor could be as a result of a clash between class times and meals which interferes with normal meal patterns. The low consumption of fruits and vegetables could be attributed to costs and their seasonality.

Majority of the students in this study had normal nutrition status (68.4\%). The relatively high level of overweight reported among the respondents could be attributed to high intake of unhealthy foods like sausages, hot dogs, sweets and beverages as witnessed in the study.

Various forms of malnutrition have been associated with women's dietary practices. Malnutrition may predispose women to non-communicable diseases like coronary heart disease, diabetes mellitus, 
overweight and obesity. The study results showed that underweight was significantly higher among students who had lower MDDS-W while Overweight was found to be higher among those who did not frequently consume fruits and vegetables. The findings of this study compares with a previous study that reported that malnutrition was more prevalent among adolescents who consumed inadequate amounts of fruits and vegetables. ${ }^{[16]}$ Fruits and vegetables contain fibers that help with digestion and weight control.

\section{Conclusion}

Findings of this study demonstrated high frequency of intake of unhealthy foods like soft drinks, sausages, hotdogs and sweets. The results illustrated a significant number of female students had sub optimal nutrition status. Proper dietary practices ensure female students meet their nutrition requirements for optimum nutrition status. Nutrition status had a significant relationship with dietary practices. Policy makers in the ministry of health and education should scale up intervention programs aimed at improving dietary practices among women of reproductive age. University eating premises should also find ways of ensuring that the food and meals available are nutritious, varied, convenient, acceptable and affordable. This would ensure that students are discouraged from relying on unhealthy and convenient fast foods that expose them to poor nutrition status.

\section{Abbreviations}

MDDS-W: Minimum dietary diversity score - Women

BMl: Body mass index

FFQ: Food frequency questionnaire

SD: Standard deviation

\section{Declarations}

\section{Ethics approval and consent to participate}

Approval to conduct the research was sought from Kenyatta University graduate school and ethical clearance obtained from Ethical Review Committee of Kenyatta University. A research permit was obtained from the National Council for Science Technology and Innovation (NACOSTI). Permission was also sought from the Kenyatta University administration. Participation was voluntary through informed written consent from the respondents. Confidentiality and privacy of the data collected was assured and maintained during and after the study.

\section{Consent for publication}

Not applicable 


\section{Availability of data and materials}

The data sets used and analysed during the current study are available from the corresponding author on reasonable request.

\section{Competing interests}

The authors declare that they have no competing interests.

\section{Funding}

None

\section{Authors' contributions}

GW conceived the study. GW designed the study with assistance from PC and EN. GW collected data from the field, conducted data analysis and wrote the manuscript. All authors read and approved the final manuscript.

\section{Acknowledgments}

The authors would like to thank Kenyatta University and NACOSTI for ethical clearance and the study participants for their cooperation during data collection.

\section{References}

1. Isa KA, Masuri MG. The association of breakfast consumption habit, snacking behavior and body mass index among university students. Am. J. Food. Nutr. 2011;1(2):55-60. Google Scholar View Article 2. Soriano JM, Moltó JC, Manes J. Dietary intake and food pattern among university students. Nutrition Research. 2000 Sep 1;20(9):1249-58. Google Scholar 3. Manwa L. University Students' Dietary Patterns: A Case of a University in Zimbabwe. Journal of Emerging Trends in Educational Research and Policy Studies. 2013 Feb 1;4(1):191. Google Scholar 4. Kinyua LW. Association of Nutrition Knowledge and Attitude with Dietary Practices and Nutritional Status of Female Undergraduate Students Attending University Colleges within Nairobi Metropolis (Unpublished Doctoral Dissertation). The University of Nairobi, Kenya. 2013. View Article 5. Haddad LJ, Hawkes C, Achadi E, et al. Global Nutrition Report 2015: Actions and accountability to advance nutrition and sustainable development. Intl Food Policy Res Inst; 2015 Sep 15 Google Scholar 6. Leese HJ. Effective nutrition from conception to adulthood. Human Fertility. 2014 Dec 1;17(4):252-6. Google Scholar 7. Dean SV, Lassi ZS, Imam AM, et al. Preconception care: nutritional risks and interventions. Reproductive health. 2014 Dec;11(3):S3. Google Scholar 8. Grieger JA, Grzeskowiak LE, Clifton VL. Preconception dietary patterns in human pregnancies are associated with preterm delivery. The Journal of nutrition. 2014 Apr 30;144(7):1075-80. Google Scholar 9. Zimmermann MB. The effects of iodine deficiency in pregnancy and infancy. Paediatric and perinatal epidemiology. 2012 Jul;26:108-17. Google Scholar 10. FAO/FANTA. Introducing the minimum dietary 
diversity -women (MDD-W) global dietary diversity indicator for women. Washington, DC.2014. https://www.fantaproject.org/sites/default/files/resources/Introduce-MDD-W-indicator-brief-

Sep2014_0.pdf 11. Shill KB, Karmakar P, Kibria MG, et al. Prevalence of iron-deficiency anaemia among university students in Noakhali region, Bangladesh. Journal of health, population, and nutrition. 2014 Mar;32(1):103. Google Scholar 12. Garcia AC, Sykes L, Matthews J, et al. Perceived facilitators of and barriers to healthful eating among university students. Canadian Journal of Dietetic Practice and Research. 2010 May 26;71(2):e28-33. Google Scholar 13. Mehlawat, U. Dietary diversity score of college going students (17-21 years) and its association with family income in India. The Indian Journal of Nutrition and Dietetics. 2015 Jul 52(3): 277-285.

http://www.informaticsjournals.com/index.php/ijnd/article/view/2401 14. Sedodo NS, Akinlotan JV, Akinlua 0 , et al. Dietary diversity score and nutritional status of undergraduates in South West Nigeria. $J$ Obes Wt Loss Ther S. 2014;4:2. Google Scholar View Article 15. Bonaccio M, lacoviello L, De Gaetano G, et al. Investigators. The Mediterranean diet: the reasons for a success. Thrombosis research. $2012 \mathrm{Mar}$ 1;129(3):401-4. View Article 16. Otuneye AT, Ahmed PA, Abdulkarim AA, et al. Relationship between dietary habits and nutritional status among adolescents in Abuja municipal area council of Nigeria. Nigerian Journal of Paediatrics. 2017;44(3):128-35. http://dx.doi.org/10.4314/njp.v44i3.1

\section{Figures}

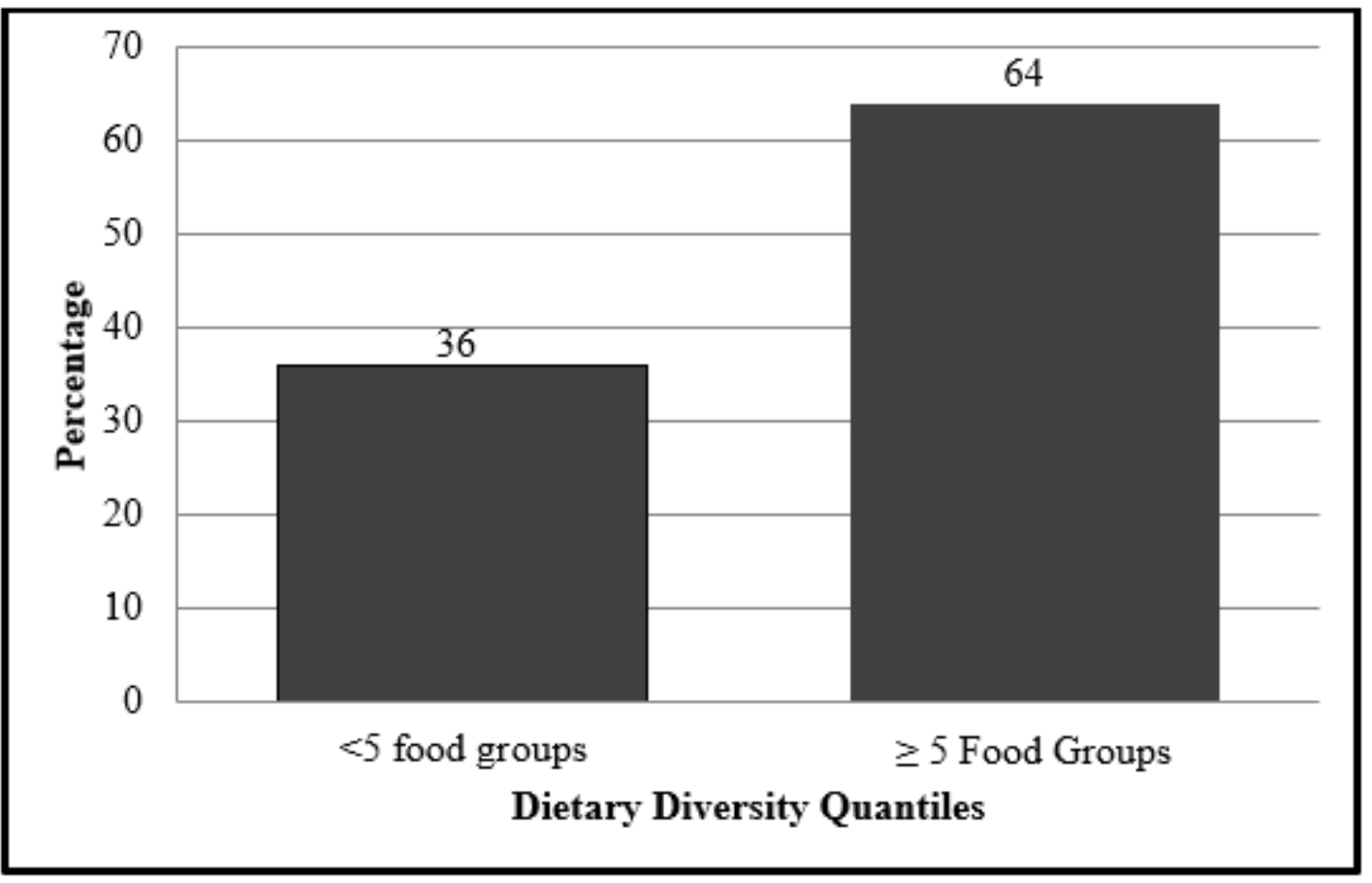

Figure 1

Respondents minimum dietary diversity scores

Figure 2 
Respondents nutrition status

Page 9/9 